\title{
Modelo de ponto crítico para estimar danos de doenças foliares do trigo em patossistema múltiplo
}

\author{
Daniel A. Bohatchuk ${ }^{1}$, Ricardo T. Casa ${ }^{1}$, Amauri Bogo ${ }^{1}$, Paulo R. Kuhnem Junior ${ }^{1}$, Erlei M. Reis ${ }^{2} \&$ Éder $^{\prime}$ \\ N. Moreira ${ }^{2}$
}

${ }^{1}$ Centro de Ciências de Agroveterinárias, Universidade do Estado de Santa Catarina - UDESC, 88520-000, Lages, SC, Brasil; ${ }^{2}$ Faculdade de Agronomia e Medicina Veterinária, Universidade de Passo Fundo - UPF, 99001-970, Passo Fundo, RS, Brasil

Autor para correspondência: Ricardo Trezzi Casa, e-mail: a2rtc@cav.udesc.br

\section{RESUMO}

As doenças foliares do trigo causam danos pela redução da atividade fotossintética da planta. O objetivo foi obter equações das funções de dano para patossistema múltiplo pela relação entre rendimento de grãos e incidência das doenças foliares em diferentes estádios fenológicos. Os experimentos foram conduzidos em Lages e São José do Cerrito, SC, safras 2005/06 e 2006/07, nas cultivares Ônix e BRS Louro. O gradiente das doenças foi gerado pelo número de aplicações (uma, duas e três) e três diferentes doses dos fungicidas azoxistrobina+ciproconazole $\left(40+16,60+24\right.$ e $\left.80+32 \mathrm{~g}_{\text {de i.a. ha }}{ }^{-1}\right)$, trifloxistrobina+tebuconazole $\left(25+50,50+100\right.$ e $\left.75+150 \mathrm{~g} \mathrm{de}^{2} . \mathrm{a} . \mathrm{ha}^{-1}\right)$ e piraclostrobina+epoxiconazole $\left(33,25+12,5,66,5+25\right.$ e 99,75+37,5 g de i.a. ha $\left.{ }^{-1}\right)$. Cada experimento constou de 10 tratamentos, distribuídos em blocos ao acaso, com quatro repetições. A incidência das doenças foliares foi avaliada nos estádios de crescimento EC 31, 34, 40, 52 e 60 da escala de Zadoks. Houve correlação significativa para BRS Louro nos dois locais e safras, nos estádios EC 40 e EC 52 . No entanto, para Ônix somente foi significativo em São José do Cerrito, nas duas safras. A variação entre os coeficientes de dano das equações indica necessidade da continuidade desta pesquisa em diferentes locais e anos, em cultivares com reações semelhantes às doenças foliares testadas neste trabalho.

Palavras-chave: controle químico, limiar de dano econômico, Triticum aestivum.

\begin{abstract}
A critical-point model to estimate damage caused by wheat leaf diseases in a multiple pathosystem

Wheat leaf diseases cause damage by reducing photosynthetic activity in leaves. The objective was to obtain damage model equations for a wheat multiple pathosystem, by examining the relation between grain yield and the incidence of leaf diseases at different plant growth stages. The experiments were carried in Lages and São José do Cerrito, SC, during the 2005/06 and 2006/07 crop seasons with cultivars Ônix and BRS Louro. The gradient of disease incidence was obtained by the number of fungicide applications (one, two, and three) and three different fungicide rates: azoxystrobin+cyproconazol $\left(40+16,60+24\right.$ and $80+32 \mathrm{~g}$ of a.i. ha $\left.{ }^{-1}\right)$, trifloxystrobin + tebuconazol $(25+50$, $50+100$ and $75+150 \mathrm{~g}$ of a.i. $\left.\mathrm{ha}^{-1}\right)$ and pyraclostrobin+epoxyconazol $\left(33.25+12.5,66.5+25\right.$ e $99.75+37.5 \mathrm{~g}$ of a.i. ha $\left.{ }^{-1}\right)$. Each experiment consisted of ten treatments distributed according to the random block scheme with four repetitions. The leaf disease incidence was evaluated at the growth stages EC 31, 34, 40, 52 and 60 according to Zadok's scale. There was significant correlation between two places and harvests for BRS Louro cultivar in the 40 and 50 plant growth stages. However, this was only significant for the Ônix cultivar in São José do Cerrito in both harvests. The variation between the damage model equations indicates the necessity to continue this research in different places and years, using cultivars with similar leaf disease reactions to those tested in this work.
\end{abstract}

Keywords: chemical control, economic damage threshold, Triticum aestivum.

\section{INTRODUÇÃO}

A Região Sul do Brasil responde pela maior parte da produção nacional de trigo. O estado de Santa Catarina apresenta a menor área cultivada entre os estados do sul do Brasil (Conab, 2007), no entanto, alguns produtores têm obtido produtividades superiores a $3.600 \mathrm{~kg} \cdot \mathrm{ha}^{-1}$. O país tem condições de solo, de clima, de material genético e de tecnologia disponíveis para incrementar a produtividade do

Parte da Dissertação de Mestrado do primeiro autor. Universidade do Estado de Santa Catarina. Lages SC. 2007. trigo (Bisotto, 2005). Porém, as doenças foliares, que incidem sobre o trigo, constituem uma das principais causas que levam a reduções na produtividade. As condições climáticas da Região Sul do Brasil favorecem tanto a ocorrência como o aumento da intensidade das doenças, principalmente pelo excesso de chuva durante o ciclo da cultura (Reis \& Casa, 2005a). Dentre as principais doenças foliares encontram-se o oídio [Blumeria graminis f.sp. tritici (DC) Speer], a ferrugem da folha (Puccinia recondita Dietel \& Holw.; sin. Puccinia triticina Erikss.), e as manchas foliares, representadas pela mancha amarela [Drechslera tritici-repentis (Died) Shoemaker], pela mancha marrom [Bipolaris sorokiniana (Sacc.) Shoemaker] e pela septoriose [Septoria nodorum (Berk.) Berk.]. 
As manchas foliares ocorrem e têm maior intensidade quando são utilizadas sementes infectadas ou quando o trigo é cultivado sob monocultura em sistema de plantio direto (Reis et al., 1998; Zambolim et al., 2000). A ferrugem da folha e o oídio são de ocorrência freqüente em todas as safras agrícolas nas cultivares suscetíveis, sendo pouco influenciadas por práticas culturais (Reis \& Casa, 1997). Os danos causados pelas doenças foliares são atribuídos principalmente à redução da atividade fotossintética da planta.

O uso de cultivar resistente é a medida de controle mais eficaz, porém, ainda não foi desenvolvida, por pesquisa, uma única cultivar resistente para todas as doenças foliares (Reunião, 2006). Outras medidas como uso de sementes sadias, tratamento de sementes com fungicidas, rotação de culturas, eliminação de plantas voluntárias e de hospedeiros alternativos, auxiliam na redução do inóculo. Em geral, a redução do crescimento das doenças no campo nas cultivares suscetíveis é feita pelo controle químico (Reis \& Casa, 2005a). De acordo com Goulart et al. (1998), o uso de fungicidas constitui-se em uma ferramenta importante para estabilizar a produtividade de trigo. Respostas significativas no controle de doenças foliares têm sido obtidas com aplicação de fungicidas nos órgãos aéreos (Barros et al., 2006). Entretanto, Zambolim et al. (2003) apontam que a aplicação de defensivos agrícolas, sem nenhum critério técnico, proporcionado pelo modelo convencional de agricultura, provoca o aumento no custo de produção e a contaminação do agro-ecossistema. No caso do trigo, o controle químico pode onerar os custos de produção devido à falta de um critério que determine o momento correto para iniciar a aplicação, sendo recomendado para lavouras com alto potencial produtivo (Reis et al., 2001; Reis \& Casa, 2005b). A pesquisa dispõe de critérios com base na intensidade de doença (Reis et al., 1996; Reunião da Comissão 2006) ou m certos estádios de crescimento (Fernandes \& Picinini, 1999; Reunião, 2006). Estes critérios são utilizados pela assistência técnica, porém, em ambos os casos, não consideram a viabilidade econômica para justificar o emprego de fungicidas. O Limiar de Dano Econômico (LDE) é um critério racional para aplicação de fungicida que vem sendo utilizado para algumas doenças do trigo. No Brasil a pesquisa desenvolveu equações de função de dano que subsidiam o cálculo do LDE para oídio (Reis et al., 1997), ferrugem da folha (Reis et al., 2000; Reis et al., 2006) e manchas foliares (Casa et al., 2001). Entretanto, estas equações não consideram o patossistema múltiplo, uma vez que as doenças foliares podem ocorrer simultaneamente na mesma planta.

Para determinaro dano causado por uma oumais doenças, usualmente, analisam-se as relações entre intensidade da doença e dano, utilizando modelos matemáticos como de ponto crítico, múltiplos pontos, integrais, de superfície de resposta e modelos sinecológicos. No modelo de ponto crítico é possível identificar um determinado estádio de desenvolvimento do hospedeiro, no qual a intensidade de doença presente está correlacionada com o dano futuro (Vale et al., 2004). Neste trabalho procurou-se determinar as equações das funções de dano para patossistema múltiplo em trigo, utilizando duas cultivares com reações contrastantes a suscetibilidade de doenças foliares. $\mathrm{O}$ gradiente das doenças e o dano no rendimento de grãos foram gerados pelo método da parcela experimental empregando-se o modelo de ponto crítico.

\section{MATERIAL E MÉTODOS}

Foram conduzidos oito experimentos no campo, durante as safras agrícolas de 2005/06 e 2006/07. Quatro experimentos foram instalados no Centro de Ciências Agroveterinárias da Universidade do Estado de Santa Catarina, CAV/UDESC, em Lages SC, e outros quatro, instalados no Centro de Educação Profissional Caetano Costa, CEDUP, em São José do Cerrito SC. Os municípios de Lages e de São José do Cerrito estão localizados no Planalto Sul de Santa Catarina, cujas coordenadas geográficas são $27^{\circ} 50^{\prime}$ de latitude sul e $50^{\circ} 29^{\prime}$ de longitude oeste; e $28^{\circ} 55^{\prime}$ de latitude sul e $51^{\circ} 08^{\prime}$ de longitude oeste, respectivamente. $\mathrm{O}$ solo da área experimental nos municípios é classificado como Cambissolo Húmico Alumínico Léptico, em Lages, e Nitossolo Háplico Alumínico (terra Bruna estruturada), em São José do Cerrito.

Nos dois locais, foram utilizadas duas cultivares de trigo: a cultivar Ônix (suscetível a ferrugem da folha, mancha marrom e mancha amarela) e a cultivar BRS Louro (moderadamente suscetível a oídio, ferrugem da folha, mancha marrom e mancha amarela) (Reunião da Comissão 2006). Em Lages, os experimentos foram conduzidos emárea de semeadura direta sob monocultura; enquanto em São José do Cerrito, em semeadura direta sob rotação de culturas. Como prevenção ao ataque de insetos do solo e pulgões da parte aérea logo após a emergência, as sementes foram tratadas com inseticida imidacloprida ( $24 \mathrm{~g}$ i.a. para $100 \mathrm{~kg}$ de sementes). A semeadura foi realizada nos dias 12 de julho de 2005 e 10 de julho de 2006, em Lages, e dia 20 de julho de 2005 e 18 de julho de 2006, em São José do Cerrito, utilizando-se semeadora de plantio direto própria para parcelas experimentais. A densidade populacional foi de aproximadamente 350 sementes por $\mathrm{m}^{2}$. $\mathrm{Na}$ adubação de base, foram aplicados $400 \mathrm{~kg} \cdot \mathrm{ha}^{-1}$ da fórmula 10-20-20 (N-P-K) e na adubação de cobertura, $200 \mathrm{~kg} \cdot$ ha $^{-1}$ de uréia $(45 \%$ de N), feita 35 dias após a semeadura. $\mathrm{O}$ controle de plantas daninhas foi feito em dessecação antes da semeadura, utilizando-se o herbicida glifosato (72 g i.a. ha-1) e, em pós-emergência, com o herbicida metsulfurom metílico (6 g i.a. ha $\left.{ }^{-1}\right)$. Lagartas e pulgões foram controlados com inseticida imidacloprida + beta-ciflurina (40 +5 g i.a. ha- $\left.{ }^{-1}\right)$.

Para obter as equações de dano, foi gerado o gradiente das doenças (Sah \& Mackenzie, 1987), através do uso de diferentes doses de fungicida (três) e do número de aplicações (uma, duas e três). Em Lages, para cultivar Ônix, foram utilizados azoxistrobina + ciproconazole (Priori Xtra 40+16, $60+24$ e $80+32$ g de i.a. ha ${ }^{-1}$ ) e, para BRS Louro, trifloxistrobina + tebuconazole (Nativo 25+50, 50+100 e 75+150 g de i.a. ha $\left.^{-1}\right)$. Em São José do Cerrito, para as duas cultivares foi utilizado o fungicida piraclostrobina + epoxiconazole (Opera $33,25+12,5,66,5+25$ e 99,75+37,5 g de i.a. ha $\left.{ }^{-1}\right)$. O intervalo de tempo entre as aplicações correspondeu ao tempo de persistência dos fungicidas para a dose recomendada para 
a cultura. As aplicações foram feitas com pulverizador costal de precisão, com pressão constante gerada por $\mathrm{CO}_{2}$, num volume de calda de 200 L.ha $^{-1}$. A combinação entre doses e número de aplicações, mais uma testemunha sem fungicida, totalizou dez tratamentos por experimento. $\mathrm{O}$ delineamento experimental foi de blocos ao acaso, com quatro repetições, perfazendo um total de 40 parcelas. As unidades experimentais constaram de parcelas de cinco metros de comprimento com cinco linhas de semeadura.

A incidência das doenças foi quantificada nos estádios de crescimento EC 31 (primeiro nó visível), EC 34 (quarto nó visível), EC 40 (emborrachamento), EC 52 (um quarto da inflorescência emergida) e EC 60 (início da antese) da escala de Zadoks (Zadoks et al., 1974), avaliando todas as folhas verdes e expandidas de dez plantas, coletadas ao acaso, nas três linhas centrais de cada parcela. Considerou-se infectada a folha com a presença, de no mínimo, uma mancha com sintoma característico e, no caso da ferrugem, aquela com, no mínimo, uma pústula com esporulação visível.

A colheita manual do trigo foi feita cortando-se todas as espigas presentes dentro de uma moldura de madeira com área de $0,25 \mathrm{~m}^{2}$. Em cada parcela, coletaram-se três amostras. As espigas foram trilhadas em máquina estacionária, com posterior limpeza, secagem e pesagem dos grãos. O peso da massa seca de grãos na área útil da parcela foi convertido para hectare. Procedeu-se a análise de regressão entre a variável independente, incidência foliar das doenças, e variável dependente, rendimento de grãos, para cada estádio de crescimento da cultura, obtendo-se as equações das funções de dano. As equações obtidas também foram ajustadas por tonelada de trigo colhido visando facilitar a comparação dos coeficientes de dano para cada estádio de desenvolvimento da planta, nas duas cultivares, locais e safras agrícolas.

\section{RESULTADOS E DISCUSSÃO}

Nos dois locais de cultivo e nas duas safras agrícolas, as condições climáticas foram favoráveis para infecção natural dos patógenos e crescimento das doenças foliares, obtendo-se o gradiente das doenças e do rendimento de grãos para ambas cultivares de trigo. O oídio predominou no trigo BRS Louro, no início do alongamento na safra 2005, em São José do Cerrito e em Lages. Nas demais fases, a ferrugem da folha e a mancha amarela foram as doenças predominantes. A mancha amarela junto com a ferrugem da folha, no início do alongamento, e somente a ferrugem da folha, a partir do alongamento, predominaram no trigo Ônix nos dois locais e nas duas safras.

Nas duas safras agrícolas foram estimados os parâmetros de 38 equações lineares da função de dano, sendo 18 para Lages (Tabela 1) e 20 para São José do Cerrito (Tabela 2).

TABELA 1 - Equações da função de dano para o patossistema múltiplo, originais e ajustadas para tonelada, para as cultivares de trigo BRS Louro e Ônix, em diferentes estádios fenológicos de crescimento das plantas, geradas em Lages SC, nas safras agrícolas de 2005 e 2006

\begin{tabular}{|c|c|c|c|c|c|}
\hline Cultivar/Ano & $\mathbf{E C}^{*}$ & Equação original & $\mathbf{P}={ }^{* * *}$ & $\mathbf{R}^{2}$ & Equação ajustada / $t$ \\
\hline \multicolumn{6}{|l|}{ BRS Louro } \\
\hline \multirow[t]{5}{*}{2005} & 31 & $\mathrm{R}=3.552,4-16,207 \mathrm{I}$ & 0,0004 & 0,84 & $\mathrm{R}=1.000-4,560 \mathrm{I}$ \\
\hline & 34 & $\mathrm{R}=3.506,0-11,318 \mathrm{I}$ & 0,0019 & 0,77 & $\mathrm{R}=1.000-3,228 \mathrm{I}$ \\
\hline & 40 & $\mathrm{R}=3.589,9-11,649 \mathrm{I}$ & 0,0013 & 0,79 & $\mathrm{R}=1.000-3,245 \mathrm{I}$ \\
\hline & 52 & $\mathrm{R}=3.751,7-10,714 \mathrm{I}$ & 0,0043 & 0,71 & $\mathrm{R}=1.000-2,856 \mathrm{I}$ \\
\hline & 60 & $\mathrm{R}=3.752,3-8,313 \mathrm{I}$ & 0,0480 & 0,45 & $\mathrm{R}=1.000-2,216 \mathrm{I}$ \\
\hline \multirow[t]{5}{*}{2006} & 31 & $\mathrm{R}=3.709,7-32,408 \mathrm{I}$ & 0,0170 & 0,58 & $\mathrm{R}=1.000-8,736 \mathrm{I}$ \\
\hline & 34 & $\mathrm{R}=3.839,6-27,122 \mathrm{I}$ & 0,0003 & 0,86 & $\mathrm{R}=1.000-7,064 \mathrm{I}$ \\
\hline & 40 & $\mathrm{R}=3.809,2-21,666 \mathrm{I}$ & 0,0006 & 0,83 & $\mathrm{R}=1.000-5,688 \mathrm{I}$ \\
\hline & 52 & $R=3.900,6-16,475 \mathrm{I}$ & 0,0020 & 0,77 & $\mathrm{R}=1.000-4,224 \mathrm{I}$ \\
\hline & 60 & $\mathrm{R}=3.968,3-13,500 \mathrm{I}$ & 0,0270 & 0,53 & $\mathrm{R}=1.000-3,402 \mathrm{I}$ \\
\hline \multicolumn{6}{|l|}{ Ônix } \\
\hline \multirow[t]{4}{*}{2005} & 31 & $\mathrm{R}=3.134,7-7,454 \mathrm{I}$ & 0,21413 & 0,18 & $\mathrm{R}=1.000-2,376 \mathrm{I}$ \\
\hline & 34 & $\mathrm{R}=3.188,9-12,169 \mathrm{I}$ & 0,06054 & 0,37 & $\mathrm{R}=1.000-3,813 \mathrm{I}$ \\
\hline & 40 & $\mathrm{R}=2.637,1-2,981 \mathrm{I}$ & 0,80883 & 0,01 & $\mathrm{R}=1.000-1,130 \mathrm{I}$ \\
\hline & 52 & $\mathrm{R}=3.243,3-8,186 \mathrm{I}$ & 0,02026 & 0,51 & $\mathrm{R}=1.000-2,522 \mathrm{I}$ \\
\hline \multirow[t]{4}{*}{2006} & 31 & $\mathrm{R}=3.531,6-8,185 \mathrm{I}$ & 0,48368 & 0,06 & $\mathrm{R}=1.000-2,377 \mathrm{I}$ \\
\hline & 34 & $\mathrm{R}=2.773,5-15,594 \mathrm{I}$ & 0,18463 & 0,20 & $\mathrm{R}=1.000-5,621 \mathrm{I}$ \\
\hline & 40 & $\mathrm{R}=2.907,0-9,699 \mathrm{I}$ & 0,12348 & 0,27 & $\mathrm{R}=1.000-3,333 \mathrm{I}$ \\
\hline & 52 & $\mathrm{R}=3.646,5-8,388 \mathrm{I}$ & 0,06991 & 0,35 & $\mathrm{R}=1.000-2,298 \mathrm{I}$ \\
\hline
\end{tabular}

*EC - Estádio de Crescimento (Zadoks et al., 1974): EC 31 (primeiro nó visível), EC 34 (quarto nó visível), EC 40 (emborrachamento), EC 52 (um quarto da inflorescência emergida) e EC 60 (início da antese).

${ }^{* *}$ Probalidade de erro. 
Todas variáveis da função de dano foram estimados por análise de regressão. As equações ajustadas forneceram informação do coeficiente de dano por tonelada de trigo para cada $1 \%$ de incidência foliar (Tabelas 1 e 2).

Em Lages, na safra 2005, na cultivar BRS Louro, os valores de coeficiente de dano variaram entre $2,21 \mathrm{~kg}$ e $4,56 \mathrm{~kg}$ para cada $1 \%$ de incidência foliar, considerando o rendimento de $1.000 \mathrm{~kg} \cdot \mathrm{ha}^{-1}$ (Tabela 1). Em 2006, os valores ficaram entre $3,40 \mathrm{~kg}$ e $8,73 \mathrm{~kg}$. Para Ônix, durante a safra 2005 os valores de dano foram entre $1,13 \mathrm{~kg}$ e 3,81 kg para cada $1 \%$ de incidência, e, em 2006, entre $2,37 \mathrm{~kg}$ e $5,62 \mathrm{~kg}$ (Tabela 1). Em São José do Cerrito, para BRS Louro, em 2005, obtiveram-se valores de dano entre 4,72 kg e 17,74 kg. Em 2006 , os valores variaram de $9,01 \mathrm{~kg}$ e $52,63 \mathrm{~kg}$. A cultivar Ônix, em 2005, apresentou valores de danos que variaram entre $3,51 \mathrm{~kg}$ e $12,64 \mathrm{~kg}$, e, em 2006, com valores entre 4,63 kg e $52,07 \mathrm{~kg}$ (Tabela 2, Figura 2).

Nas duas safras os maiores danos foram observados quando ocorreram nos estádios iniciais de desenvolvimento (EC 31 e 34 de Zadoks et al., 1974) (Tabelas 1 e 2). Valores semelhantes foram obtidos por Cook et al. (1999), justificando que epidemias de doenças foliares iniciadas antes da emergência da folha bandeira apresentam grande impacto sobre o rendimento de grãos. Os maiores danos nestes estádios de desenvolvimento podem ser explicados uma vez que, nestas fases, são definidos os principais componentes do rendimento de grãos de trigo (Frederick \& Bauer, 1999). Nesse caso, a ocorrência conjunta das doenças foliares nestas fases pode interferir no número de grãos por $\mathrm{m}^{2}$, que é determinado pelo número de afilhos e pelo número de grãos por espiga.

Considerando os valores de coeficientes de dano em relação ao local de cultivo, em geral, São José do Cerrito foi o que apresentou os maiores valores (Tabelas 1 e 2). Os resultados foram contrários à hipótese de que o cultivo sob rotação proporcionaria menor dano, comparado ao sistema de monocultivo realizado em Lages, por reduzir a quantidade de inóculo dos patógenos necrotróficos causadores de manchas foliares. Por outro lado, salienta-se que, em São José do Cerrito, houve predomínio do oídio e da ferrugem da folha, respectivamente nas cultivares BRS Louro e Ônix, nos primeiros estádios de desenvolvimento. Tal fato pode ter ocorrido devido à presença de lavouras de trigo próximas a área do experimento; diferente de Lages, onde houve predomínio da mancha amarela nos estádios iniciais e onde não existia lavoura de trigo nas proximidades da área experimental que fica localizada dentro da cidade de Lages.

TABELA 2 - Equações da função de dano para o patossistema múltiplo, originais e ajustadas para tonelada, para as cultivares de trigo BRS Louro e Ônix, em diferentes estádios fenológicos de crescimento das plantas geradas em São José do Cerrito SC, nas safras agrícolas de 2005 e 2006

\begin{tabular}{|c|c|c|c|c|c|}
\hline Cultivar/Ano & $\mathbf{E C}^{*}$ & Equação original & $\mathbf{P}=* *$ & $\mathbf{R}^{2}$ & Equação ajustada / $t$ \\
\hline \multicolumn{6}{|l|}{ BRS Louro } \\
\hline \multirow[t]{5}{*}{2005} & 31 & $\mathrm{R}=4.674-82,937 \mathrm{I}$ & 0,0125 & 0,61 & $\mathrm{R}=1.000-17,74 \mathrm{I}$ \\
\hline & 34 & $\mathrm{R}=3.781,9-24,535 \mathrm{I}$ & 0,0128 & 0,61 & $\mathrm{R}=1.000-6,487 \mathrm{I}$ \\
\hline & 40 & $\mathrm{R}=4.019,4-21,792 \mathrm{I}$ & 0,0002 & 0,87 & $\mathrm{R}=1.000-5,421 \mathrm{I}$ \\
\hline & 52 & $\mathrm{R}=4.219,0-19,949 \mathrm{I}$ & 0,0003 & 0,85 & $\mathrm{R}=1.000-4,728 \mathrm{I}$ \\
\hline & 60 & $\mathrm{R}=30.564-274,9 \mathrm{I}$ & 0,0121 & 0,61 & $\mathrm{R}=1.000-8,994 \mathrm{I}$ \\
\hline \multirow[t]{5}{*}{2006} & 31 & $\mathrm{R}=3.496,12-184,02 \mathrm{I}$ & 0,0013 & 0,65 & $\mathrm{R}=1.000-52,63 \mathrm{I}$ \\
\hline & 34 & $\mathrm{R}=3.713,55-181,24 \mathrm{I}$ & 0,00003 & 0,67 & $\mathrm{R}=1.000-48,80 \mathrm{I}$ \\
\hline & 40 & $\mathrm{R}=3.763,69-42,06 \mathrm{I}$ & 0,00001 & 0,92 & $\mathrm{R}=1.000-11,18 \mathrm{I}$ \\
\hline & 52 & $\mathrm{R}=3.797,18-34,21 \mathrm{I}$ & 0,000004 & 0,94 & $\mathrm{R}=1.000-9,01 \mathrm{I}$ \\
\hline & 60 & $\mathrm{R}=3.822,20-38,67 \mathrm{I}$ & 0,0011 & 0,75 & $\mathrm{R}=1.000-10,12 \mathrm{I}$ \\
\hline \multicolumn{6}{|l|}{ Ônix } \\
\hline \multirow[t]{5}{*}{2005} & 31 & $\mathrm{R}=4.595,4-58,104 \mathrm{I}$ & 0,1383 & 0,28 & $\mathrm{R}=1.000-12,64 \mathrm{I}$ \\
\hline & 34 & $\mathrm{R}=3.930,2-19,977 \mathrm{I}$ & 0,0835 & 0,36 & $\mathrm{R}=1.000-5,082 \mathrm{I}$ \\
\hline & 40 & $\mathrm{R}=4.396,2-16,907 \mathrm{I}$ & 0,0243 & 0,53 & $\mathrm{R}=1.000-3,845 \mathrm{I}$ \\
\hline & 52 & $\mathrm{R}=4.557,6-15,998 \mathrm{I}$ & 0,0051 & 0,69 & $\mathrm{R}=1.000-3,510 \mathrm{I}$ \\
\hline & 60 & $\mathrm{R}=9.427,9-60,417 \mathrm{I}$ & 0,0956 & 0,34 & $\mathrm{R}=1.000-6,408 \mathrm{I}$ \\
\hline \multirow[t]{5}{*}{2006} & 31 & $\mathrm{R}=3.866,08-201,33 \mathrm{I}$ & 0,4175 & 0,74 & $\mathrm{R}=1.000-52,07 \mathrm{I}$ \\
\hline & 34 & $\mathrm{R}=3.957,18-96,41 \mathrm{I}$ & 0,0015 & 0,67 & $\mathrm{R}=1.000-24,36 \mathrm{I}$ \\
\hline & 40 & $\mathrm{R}=4.290,30-28,55 \mathrm{I}$ & 0,0008 & 0,80 & $R=1.000-6,65 \mathrm{I}$ \\
\hline & 52 & $\mathrm{R}=4.434,37-20,53 \mathrm{I}$ & 0,0007 & 0,79 & $\mathrm{R}=1.000-4,63 \mathrm{I}$ \\
\hline & 60 & $\mathrm{R}=5.076,76-24,59 \mathrm{I}$ & 0,0006 & 0,80 & $\mathrm{R}=1.000-4,84 \mathrm{I}$ \\
\hline
\end{tabular}

*EC - Estádio de Crescimento (Zadoks et al., 1974): EC 31 (primeiro nó visível), EC 34 (quarto nó visível), EC 40 (emborrachamento), EC 52 (um quarto da inflorescência emergida) e EC 60 (início da antese).

${ }^{* *}$ Probalidade de erro. 

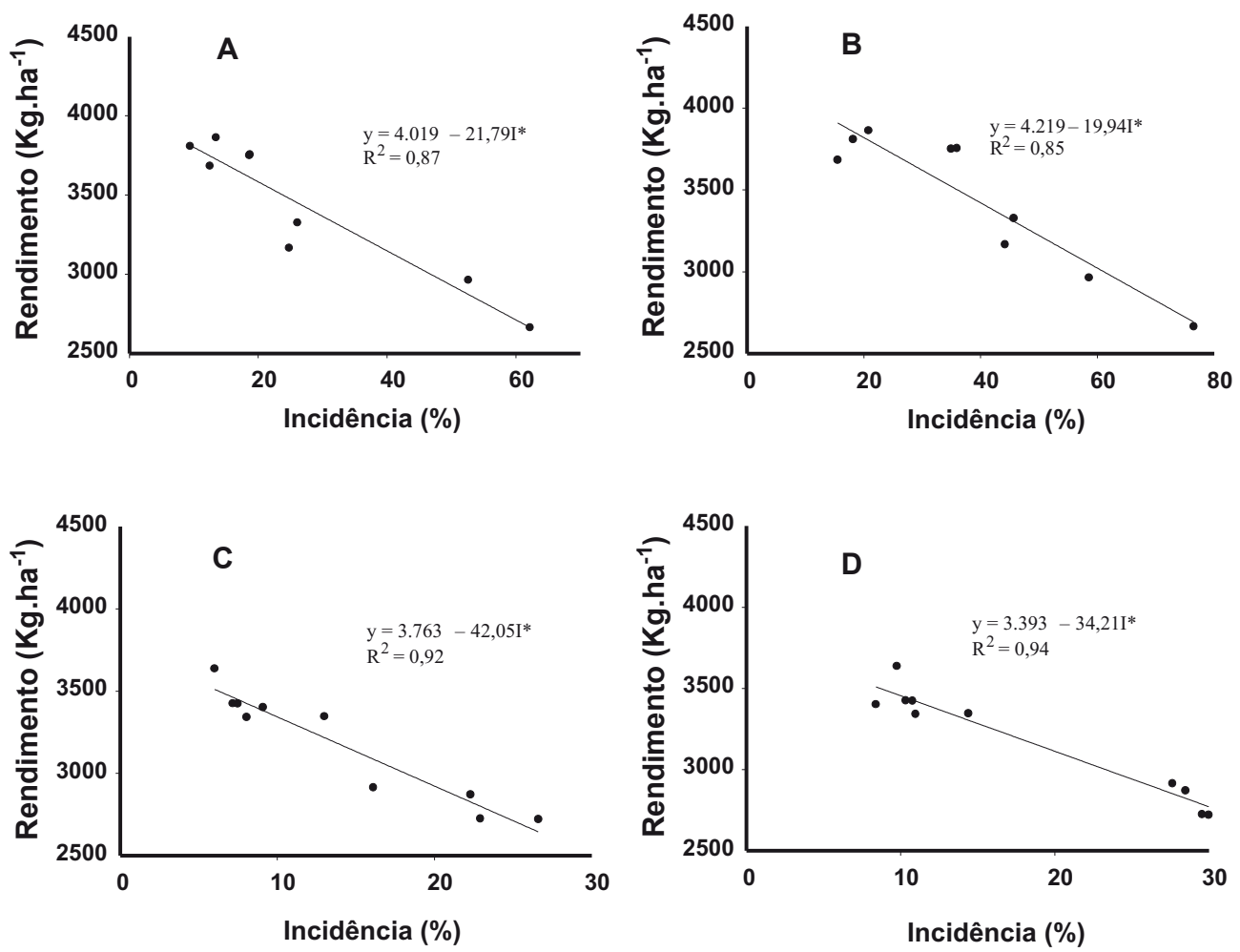

FIG. 1 - Relação entre rendimento de grãos e incidência de doenças fúngicas foliares na cultivar de trigo Ônix nos estádios de um quarto da inflorescência emergida (A. 2005; C. 2006), emborrachamneto (B. 2006) e início da antese (D. 2006) em São José do Cerrito. Lages SC, 2007.
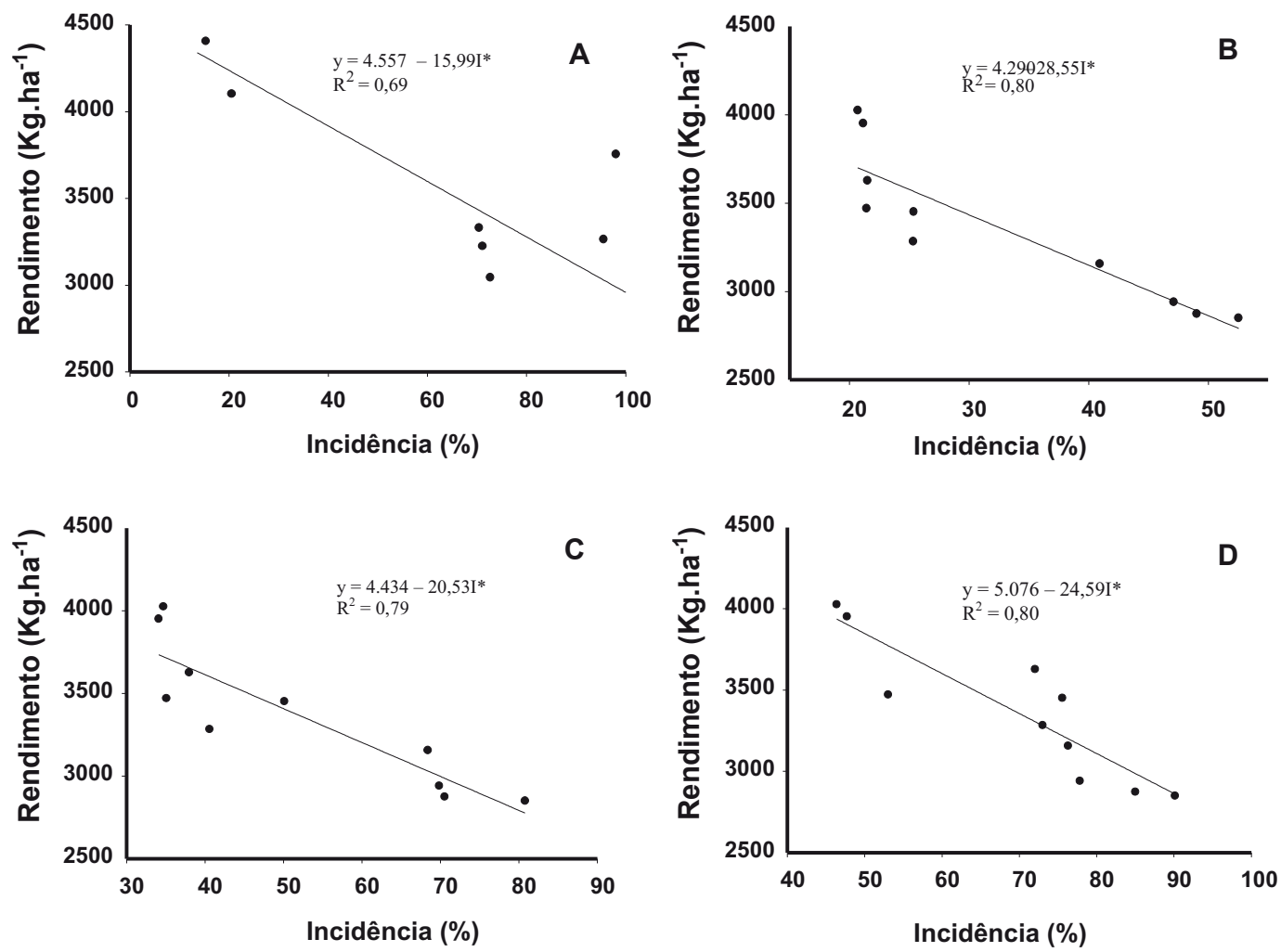

FIG. 2 - Relação entre rendimento de grãos e incidência de doenças fúngicas foliares na cultivar de trigo BRS Louro nos estádios de emborrachamneto (A. 2005; C. 2006) e um quarto da inflorescência emergida (B. 2005; D. 2006) em São José do Cerrito. Lages SC, 2007. 
$\mathrm{Na}$ cultivar Ônix, foram geradas seis correlações significativas, sendo uma na safra 2005 na cidade de Lages e cinco na safra 2006 em São José do Cerrito (Figura 1). O baixo número de correlações significativas nesta cultivar, deve-se ao fato da dificuldade em gerar o gradiente das doenças, principalmente em 2005, possivelmente pela ocorrência de duas novas raças da ferrugem da folha do trigo, insensíveis ao controle químico (Arduim et al., 2007). Para BRS Louro, houve correlação significativa em todas as 20 equações, com destaque para os estádios fenológicos EC 40 e EC 52 (Figura 2). Nesses dois estádios, em São José do Cerrito, geraram-se os maiores coeficientes de correlação, indicando que o rendimento de grãos sofreu interferência pelas diferentes incidências das doenças foliares (Tabela 2). Tais resultados demonstram que essas equações podem ser utilizadas em um cálculo do LDE.

Reis et al. (2001) e Indicações (2005) apresentam equações de dano isoladamente para cada doença foliar do trigo: ferrugem da folha em cultivares suscetíveis $(\mathrm{R}=1.000$ $-6,08 \mathrm{I})$, ferrugem da folha em cultivares com resistência de planta adulta $(\mathrm{R}=1.000-3,33 \mathrm{I})$, oídio $(\mathrm{R}=1.000-4,2 \mathrm{I}) \mathrm{e}$ manchas foliares $(\mathrm{R}=1.000-5,7 \mathrm{I})$, com a finalidade de uso no cálculo do limiar de dano econômico (LDE). Neste caso, para a determinação do LDE toma-se como base a fórmula de Munford \& Norton (1984), modificada para doenças foliares em trigo (Reis et al., 2001): I= Cc / (Pp x Cd) x Ec, onde $\mathrm{I}=$ incidência da doença, $\mathrm{Cc}=$ custo de controle por hectare, $\mathrm{Pp}=$ preço de venda trigo $(\mathrm{t}), \mathrm{Cd}=$ coeficiente de dano (obtido da equação da função de dano) e Ec $=$ eficiência do controle do fungicida. Além de ser uma equação para cada doença, estas foram obtidas a partir de várias equações em diferentes estádios fenológicos, fornecendo assim o coeficiente de dano médio. Todas as cultivares de trigo, disponíveis pela pesquisa, apresentam no campo, suscetibilidade a mais de uma doença (Reunião, 2006).

A variação entre os coeficientes de dano das equações indica necessidade da continuidade desta pesquisa em diferentes locais e anos em cultivares com reações semelhantes às doenças foliares testadas neste trabalho, que possam vir a auxiliar na tomada de decisão do momento de proceder-se o controle químico de doenças foliares em trigo, com base no LDE.

\section{REFERÊNCIAS BIBLIOGRÁFICAS}

Arduim Gs, Reis Em, Barcellos AL (2007) Sensibilidade de Puccinia triticina quando tratadas curativamente com diferentes fungicidas in vivo. Fitopatologia Brasileira 32(Supl.):194.

CONAB (2006). Central de Informações Agropecuárias. Safra 2006 -2007. http://www.conab.gov.br/ conabweb.

Barros BC, Castro JL, Patrício FRA (2006) Resposta de cultivares de trigo (Triticum aestivum L.) ao controle químico das principais doenças fúngicas da cultura. Summa Phytopathologica 32:239246.
Bisotto V (2005) Algumas considerações sobre a cultura do trigo. In: Indicações Técnicas da Comissão Sul-Brasileira de Pesquisa de Trigo - Trigo e Triticale. $37^{\mathrm{a}}$ Reunião da Comissão Sul-Brasileira de Pesquisa de Trigo. Cruz Alta RS. pp. 11-45.

Cook RJ, Hims MJ, Vaughan TB (1999) Effects of fungicide spray timing on winter wheat disease control. Plant Pathology 48:33-50.

Casa RT, Reis EM, Bezerra R, Herok P, Silva A (2001) Efeito de manchas foliares no rendimento de grãos de trigo. Fitopatologia Brasileira 26(Supl.):445.

Fernandes JM, Picinini EC (1999) Sistema de suporte à tomada de decisão para a otimização do uso de fungicidas na cultura do trigo. Fitopatologia Brasileira 24:9-17.

Frederick JR, Bauer PJ (1999) Physiological and numerical components of wheat yield. In: Satore EH, Slafer GA (Eds.) Wheat: ecology and physiology of yield determination. Binghamton, NY. Food Products Press. pp. 45-65.

Goulart ACP, Paiva FA, Melo Filho GA, Richetti A (1998) Controle de doenças da parte aérea do trigo pela aplicação de fungicidas viabilidade técnica e econômica. Summa Phytopathologica 24:160167.

Indicações Técnicas da Comissão Sul-Brasileira de Pesquisa de Trigo - Trigo e Triticale (2005) 37 $7^{\mathrm{a}}$ Reunião da Comissão SulBrasileira de Pesquisa de Trigo, Cruz Alta RS.

Jesus Junior WC, Vale FXR, Bergamin Filho A (2004) Quantificação de Danos e Perdas. In: Vale FXR, Jesus Junior WC, Zambolim L (Eds.) Epidemiologia aplicada ao manejo de doenças de plantas. Belo Horizonte MG. pp. 273-203.

Munford JD, Norton GA (1984) Economics of decision making in pest management. Annual Review of Entomology 29:157-174.

Reis EM, Casa RT (1997) Cereais de inverno. In: Vale FXR, Zambolim L. Controle de doenças de plantas: grandes culturas. Brasília DF. Ministério da Agricultura e do Abastecimento. 2 ed. pp. 231-189.

Reis EM, Casa RT (2005a) Danos causados por fungos associados a sementes de cereais de inverno. Summa Phytopathologica 31:138140.

Reis EM, Casa RT (2005b) Doenças do trigo. In: Kimati H, Amorim L, Rezende JAM, Bergamin Filho A, Camargo LEA (Org.) Manual de Fitopatologia. Vol 2. Doenças das plantas cultivadas. 4ª Ed. São Paulo SP. Ceres.

Reis EM, Casa RT, Forcelini CA (1996) Relação entre a severidade e a incidência da ferrugem da folha do trigo, causada por Puccinia recondita f.sp. tritici. Fitopatologia Brasileira 21:369-372.

Reis EM, Casa RT, Hoffmann LL (1997) Efeito do oídio causado por Erysiphe graminis f.sp. tritici, sobre o rendimento de grãos de trigo. Fitopatologia Brasileira 22:492-495.

Reis EM, Casa RT, Hoffmann LL, Mendes CM (2000) Efeito da ferrugem da folha no rendimento de grãos de trigo. Fitopatologia Brasileira 25:67-71.

Reis EM, Casa RT, Medeiros CA (2001) Diagnose, patometria e controle de doenças de cereais de inverno. Londrina PR. ES Comunicação S/C Ltda.

Reis EM, Leites A, Forcelini CA (2006) Relações entre intensidade da ferrugem da folha, refletância da radiação solar e rendimento de grãos na cultura do trigo Embrapa 16. Fitopatologia Brasileira 31:447-454. 
Reis EM, Medeiros CA, Casa RT (1998) Control of leaf blights of wheat by elimination of inoculum source. In: Duveiller E, Dubin HJ, Reeves J, McNab A (Org.) Helminthosporium blights of wheat: spot bloch and tan spot. México. pp. 327-332.

Reunião da Comissão Sul-Brasileira de Pesquisa de Trigo e Triticale, 38 (2006). Informações técnicas para a safra 2007: trigo e triticale. Passo Fundo: Embrapa Trigo; Comissão Sul-Brasileira de Pesquisa de Trigo e Triticale; Comissão Centro-Sul Brasileira de Pesquisa de Trigo e Triticale. Documentos. Embrapa Trigo, 69.

Sah DN, Mackenzie DR (1987) Methods of generating different levels of disease epidemics in loss experiments. In: Teng PS (Ed.) Crop loss assessment and pest management. Saint Paul MN. APS Press. pp. 90-95.

Zadoks JC, Chang TT, Konzak CF (1974) A decimal code for the growth stages of cereal. Weed Research 14:415-421.

Zambolim L, Casa RT, Reis EM (2000) Sistema plantio direto e doenças em plantas. Fitopatologia Brasileira 25:585-595.

Zambolim L, Conceição MZ, Santiago T (2003) O que Engenheiros Agrônomos devem saber para orientar o uso de produtos fitossanitários. Viçosa MG. Suprema Gráfica e Editora.

Recebido 10 Setembro 2007 - Aceito 6 Outubro 2008 - TPP 7102

Editor Associado: Lilian Amorim 